\title{
Giardiasis: Serum antibodies and coproantigens in brown rats (Rattus norvegicus) from Grenada, West Indies
}

Keshaw Tiwari, Camille Coomansingh Springer, Alfred Chikweto, Josephine Tang, Yvette Sepulveda, Amanda Leigh Smith, Nia Rametta and Ravindra Nath Sharma

Department of Pathobiology, School of Veterinary Medicine, St. George's University, Grenada, West Indies. Corresponding author: Ravindra Nath Sharma, e-mail: rsharma@sgu.edu

Co-authors: KT: ktiwari@sgu.edu, CCS: CCoomansingh@sgu.edu, AC: achikweto@sgu.edu, JT: jtang1@sgu.edu, YS: ysepulve@sgu.edu, ALS: asmith8@sgu.edu, NR: nrametta@sgu.edu

Received: 08-12-2017, Accepted: 05-02-2018, Published online: 12-03-2018

doi: 10.14202/vetworld.2018.293-296 How to cite this article: Tiwari K, Springer CC, Chikweto A, Tang J, Sepulveda Y, Smith AL, Rametta N, Sharma RN (2018) Giardiasis: Serum antibodies and coproantigens in brown rats (Rattus norvegicus) from Grenada, West Indies, Veterinary World, 11(3): 293-296.

\begin{abstract}
Aim: Giardia is a serious zoonotic parasite, which causes diarrheal disease in humans and animals including rodents. The purpose of this study was to estimate the prevalence of Giardia spp. in brown rats (Rattus norvegicus) in Grenada.

Materials and Methods: Intestinal contents from 99 and serum samples from 169 brown rats (R. norvegicus) from Grenada were collected. These samples were examined for the Giardia coproantigens using Cryptosporidium/Giardia Quik Chek assay (Tech lab ${ }^{\circledR}$ Inc., USA), and the serum was screened through an enzyme-linked immunosorbent assay (ELISA) test kit for Giardia antibody (anti-GD) ELISA kit (MyBioSource, San Diego, CA, USA).

Results: Giardia coproantigens were positive in 17.17\% (95\% confidence interval [CI]; 10.33-26.06\%) rats, whereas 55\% (95\% CI: 47.20-62.68) were positive with serum antibodies (anti-GD) to Giardia.

Conclusion: The prevalence of Giardia spp. in brown rats in Grenada was moderate based on the presence of coproantigens in the intestinal contents and antibody in serum. The findings of Giardia infections and prevalence in brown rats will help veterinarians and physicians to better plan diagnostic and preventative strategies. This is the first report of prevalence of Giardia in brown rats in Grenada.
\end{abstract}

Keywords: antibody, brown rat, coproantigens, Giardia, Grenada.

\section{Introduction}

Giardia spp. is a flagellate unicellular protozoan causing disease in humans and animals. The disease has a worldwide distribution, but in developing countries, there is a very high prevalence and incidence [1]. Based on the morphology of trophozoite, three species of Giardia are recognized: Giardia lamblia, synonymous of Giardia duodenalis, and Giardia intestinalis, is considered one of the major pathogens of humans and animals; Giardia muris of rodents, birds, and reptiles and Giardia agilis of amphibians [2]. A wide range of animals including rodents is believed to be a reservoir of $G$. lamblia $[3,4]$.

This flagellated protozoan parasite has a direct life cycle. Cysts of Giardia spp. are voided in feces from infected host and contaminate food, water, and the environment. Transmission to a new host is through ingestion of food and water contaminated with Giardia cysts or direct transmission through ingestion of cysts from person-to-person or animal-to-person

Copyright: Tiwari, et al. Open Access. This article is distributed under the terms of the Creative Commons Attribution 4.0 International License (http://creativecommons.org/licenses/by/4.0/), which permits unrestricted use, distribution, and reproduction in any medium, provided you give appropriate credit to the original author(s) and the source, provide a link to the Creative Commons license, and indicate if changes were made. The Creative Commons Public Domain Dedication waiver (http://creativecommons.org/ publicdomain/zero/1.0/) applies to the data made available in this article, unless otherwise stated. contact [5]. This direct transmission usually occurs in unhygienic conditions.

Brown rats (Rattus norvegicus) have been found infected with Giardia spp. in many countries of the world including Saudi Arabia [6], Poland [7], Turkey [8], and the USA [9]. In Grenada, there has been a report of recent increase in rats and human population, and the likelihood of transmission of zoonotic protozoan infections between these two species has increased as they share common living areas. As far as we are aware, there is no report of Giardia spp. infecting rats in Grenada. The objective of the study was to estimate the infection of Giardia spp. in brown rats in Grenada.

\section{Materials and Methods}

\section{Ethical approval}

The project entitled "Detection of zoonotic pathogens in brown rats ( $R$. norvegicus) in Grenada" was approved by the Institutional Animal Care and Use Committee (IACUC \# 16009-R) of the St. George's University, Grenada.

\section{Study area}

Grenada is the southernmost country in the Caribbean Sea with an area of $348.5 \mathrm{~km}^{2}$. The country with low hills, small trees, shrubs and tropical climate is most suitable for brown rats. The country is separated in six parishes: St. Patrick, St. Mark, St Andrew, St. John, St. George, and St. David. Since the trapping 
of rats was performed near the human dwellings, St. David and St. George parishes, which have more human population compared to other four parishes, were selected for the sample.

\section{Sample size determination}

The sample size was determined using the formula of Glenn [10]. The formula is $N=t^{2}(p)(1-p) / d^{2}$, where $\mathrm{t}=1.96, \mathrm{p}=$ estimated prevalence, and $\mathrm{d}=$ desired level of precision. Since prevalence of Giardia for Grenada is not known, we took an average of prevalence from other countries, estimated $10 \%$, and took $\mathrm{d}=5 \%$. This gave the number of samples 138 . Thus, we decided to collect 170 rats, more than estimated number.

\section{Trapping and collection of rats}

One hundred sixty-nine $(\mathrm{n}=169)$ rats were collected live from May 1 to July 14, 2017, using traps $(45 \mathrm{~cm} 1 \times 15 \mathrm{~cm} \mathrm{w} \times 15 \mathrm{~cm} \mathrm{~h})$ made manually. Traps were used with cheese or various local fruits as bait. Attempts were made to trap the rats at $10 \mathrm{~m}$ radius near the residential buildings. Traps were placed in the evening and visited next day in the morning. Traps with rats were covered with a black cloth and transported to the Necropsy Laboratory of the School of Veterinary Medicine in Grenada. Rats were anesthetized using isoflurane in oxygen through an anesthetic machine (portable vet anesthesia machine isoflurane vaporizer VET CE), manufacturer DRE (Avante Health Solution Company, USA.).

\section{Collection of samples}

The anesthetized rats were weighed and examined physically for their health. Gender was also recorded. Rats below $100 \mathrm{G}$ were grouped as young and over $100 \mathrm{G}$ as an adult following the methodology used by previous researchers $[11,12]$. Blood was collected from the heart through the thoracic wall and rats were exsanguinated this way. The abdominal cavity of rats was opened using a surgical blade and a pair of forceps. The intestinal tract with contents was placed into containers with $10 \%$ formalin until processing.

Sera were separated from the blood by centrifugation at $1500 \mathrm{~g}$ for $15 \mathrm{~min}$ at room temperature and stored at $-80^{\circ} \mathrm{C}$ till tested.

Quick check for cyst antigen and enzyme-linked immunosorbent assay (ELISA) for antibody in serum Giardia/Cryptosporidium Quick Chek assay (Tech Lab Inc., USA) was used to detect coproantigens in intestinal contents according to manufacturer's directions. Serum samples were tested for antibodies against Giardia spp. using commercial "qualitative rat Giardia antibody (anti-GD) ELISA kit" (MyBioSource, San Diego, CA, USA) following the manufacturer's recommendations.

\section{Statistical analysis}

The prevalence of Giardia spp. was compared by age and gender. The data were analyzed by the statistical methods: Fisher's exact test, using a GraphPad statistical software (http://www.graphpad.com/ quickcalcs/contingency2).

\section{Results}

From 169 tested samples, antibodies for Giardia spp. were detected in 93 rats ( $R$. norvegicus), with an overall prevalence of $55 \%$ (95\% confidence interval $[\mathrm{CI}]$ : 47.20-62.68\%). The result regarding the seroprevalence has been included in Tables-1-3. A significantly higher prevalence was found in younger rats $(\mathrm{p}<0.05)$. The difference in positive cases between St. George and St. David was statistically not significant $(\mathrm{p}>0.05)$.

Detection of Giardia spp. in intestinal contents was based on the use of antibodies against coproantigens of the organism. The positivity of rats to Giardia is presented in Table-4. Of 99 rats tested, $17.17 \%$ (95\% CI; $10.33-26.06 \%)$ were positive for coproantigens in the intestinal content (considering the sensitivity of $98.9 \%$ and specificity of $100 \%$ ).

\section{Discussion}

Conventionally, diagnosis of giardiasis in humans and animals was based on microscopic observation of cysts or trophozoites in feces. New techniques have been developed including ELISA, indirect immunofluorescence and polymerase chain reaction to detect cysts and trophozoites in feces and antibodies in serum to identify past and present infection [5]. In the present study, ELISA was used for the detection of antibodies in serum. Antibody for Giardia spp. was found in $55 \%$ of the tested rats. Results of seroepidemiology at two sites (St. George and St David) were not significantly different ( $\mathrm{p}>0.05)$.

Detection of Giardia spp. in intestinal contents is based on the use of antibodies to coproantigens of the organism. Of 99 rats tested, $17.17 \%$ were positive for coproantigens in the intestinal content. Our result is consistent with previous researchers who also found the similar prevalence of Giardia infection in brown rats. Al-Bashan and Sabra [6] reported 19\% brown rats infected with Giardia in Saudi Arabia, by microscopic examination of feces. Recently, Zeinab et al. [13], through microscopic examination, found $19.2 \%$ positivity in feces of brown rats in Iran. A lower incidence $(6.0 \%)$ in feces was found in brown rats and house rats in China [14]. The incidence of Giardia in intestine represents current infection, whereas antibody in serum indicates past exposure. In the same set of rats, we found $17.17 \%$ rats positive for coproantigens in the intestinal contents compared to $55 \%$ rats with antibodies in serum. Martin [9] reported quick clearance of Giardia spp. from the intestine as a result of acquired immunity, T-cell playing a role in the process. As a result, the young and immunocompromised animals and humans show delayed clearance of the parasite resulting in severity of the disease.

We found significantly higher prevalence in younger rats. In studies made by previous researchers, 
Table-1: Prevalence of Giardia antibody (anti-GD) in serum of brown rats from Grenada according to Parish.

\begin{tabular}{lccc}
\hline Parish positive & Number of sample tested & Number of sample positive & Percentage (\%) \\
\hline St. Georges & 76 & 46 & $60.5^{*}$ \\
St. David & 93 & 47 & $50.5^{*}$ \\
Total & 169 & 93 & 55.0 \\
\hline
\end{tabular}

$* p=0.2159$

Table-2: Prevalence of Giardia antibody (anti-GD) in serum of brown rats from Grenada according to gender.

\begin{tabular}{lccrrr}
\hline Parish & \multicolumn{2}{c}{ Male } & & \multicolumn{2}{c}{ Female } \\
\cline { 2 - 3 } \cline { 5 - 5 } & Sample tested & Sample positive (\%) & & Sample tested & Sample positive (\%) \\
\hline St. Georges & 39 & $24(61.5)$ & & 37 & $22(59.5)$ \\
St. David & 48 & $46(52.87) *$ & & 45 & $25(55.6)$ \\
Total & 87 & & & 82 & $47(57.3)^{*}$ \\
\hline
\end{tabular}

$*_{p}=0.6430$

Table-3: Prevalence of Giardia antibody (anti-GD) in serum of brown rats from Grenada according to age.

\begin{tabular}{lccrrr}
\hline Parish & \multicolumn{2}{c}{ Young } & & \multicolumn{2}{c}{ Adult } \\
\cline { 2 - 3 } & Sample tested & Positive sample (\%) & & Sample tested & Positive sample (\%) \\
\hline St. Georges & 12 & $10(83.3)$ & 64 & $36(56.2)$ \\
St. David & 7 & $5(71.4)$ & & 86 & $42(48.8)$ \\
Total & 19 & $15(78.9 \%) *$ & 150 & $78(52.0)^{*}$ \\
\hline
\end{tabular}

There is a significant association between young and adult rates $(p<0.05) . P=0.0290$

Table-4: Prevalence of coproantigens of Giardia in the intestinal content of brown rats from Grenada.

\begin{tabular}{|c|c|c|c|c|}
\hline \multirow[t]{2}{*}{ Parish } & \multicolumn{2}{|c|}{ Male } & \multicolumn{2}{|c|}{ Female } \\
\hline & Rats examined & Rats infected (\%) & Rats examined & Rats infected (\%) \\
\hline St. Georges & 23 & $4(17.4)$ & 19 & $3(15.8)$ \\
\hline St. David & 35 & $6(17.1)$ & 22 & $4(18.2)$ \\
\hline Total & 58 & $10(17.2)^{\mathrm{A}}$ & 41 & $7(17.0)^{A}$ \\
\hline
\end{tabular}

$p=1.00^{A}$

prevalence was not affected by sex or age $[15,16]$. In another study, relation of age with Giardia infection was not found [17]. Further studies are suggested to elucidate the relation of age and gender with Giardia spp. infection in rats.

\section{Conclusion}

For the first time, the prevalence of Giardia spp. was reported in brown rats in Grenada. These rats were considered as reservoir of Giardia spp., a serious zoonotic parasite, poses a threat to human population in the country. There is a need to educate the Grenadian community regarding proper maintenance of hygienic conditions in and around their dwellings to prevent survival and proliferation of the rat population. Prevention and control program be implemented by the government and health workers to prevent the contamination of food and water from Giardia spp. to combat the zoonosis.

\section{Authors' Contributions}

RNS: Planning and oversee of the research project and manuscript writing. CCS: Laboratory analysis for coproantigen. AC: Review of the manuscript. JT and ALS: Helping in collection of samples and helping CCS in laboratory work. YS and NR helping $\mathrm{KT}$ in ELISA. KT in performing ELISA and analysis of results. All authors read and approved the final manuscript.

\section{Acknowledgments}

The funding for the project from One health Research Initiative (OHRI grant 06-14-10) of St. George's University is thankfully acknowledged.

\section{Competing Interests}

The authors declare that they have no competing interests.

\section{References}

1. Adam, R.D. (2001) Biology of Giardia lamblia. Clin. Microb. Rev., 14: 447-475.

2. Flanagan, P.A. (1992) Giardia-diagnosis, clinical course and epidemiology. A review. Epidemiol. Infect., 109: 1-22.

3. Bajer, A., Bednarska, M., Pawelczyk, A., Behnke, J.M., Gilibert, F.S. and Sinski, E. (2002) Prevelance and abundance of Cryptosporidium parvum and Giardia spp. in wild rural rodents from the Mazuri lake District region of Poland. Parasitology, 125: 21-34.

4. el-Wahed, M.M.A., Salem, G.H. and el-Assaly, T.M. (1999) The role of wild rats as a reservoir of some internal parasites in Qalyobia governorate. J. Egypt Soc. Parasitol., 29: 495-503. 
5. Foubert, G. (2000) Immune response to Giardia duodenalis. Clin. Microb. Rev., 13: 35-54.

6. Al-Bashan, M.M. and Sabra, S.M. (2012) Prevalence of some enteric parasites in rats at Taif governate with special reference to associated pathogenic bacteria. Afr. J. Microb. Res., 6: 3431-3439.

7. Perek-Matysiak, A., Bunkowska-Gawlik, K., Zalesny, G. and Hildebrand, J. (2015) Small rodents as reservoirs of Cryptosporidium spp. and Giardia spp. in South-Western Poland. Ann. Agric. Environ. Med., 22: 1-5.

8. Beyhan, Y.E. and Hokelek, M. (2014) Giardia infection in laboratory rats (Rattus norvegicus) and treatment with metronidazole. Turkiye Parazitol. Derg., 38: 181-184.

9. Martin, F.H. (1986) Antibody response to Giardia muris trophozoites in mouse intestine. Infect. Immun., 52: 568-571.

10. Glenn, I.D. (2002) "Determination of Sample Size" Fact Sheet PEOD-6, a Series of the Program Evaluation and Organization Development, Florida Cooperative Extension Service Institute 2002.

11. Pirre, B., Peter, D. and Daniel, H. (2011) Age, season, and spatiotemporal factors affecting the prevalence of Echinococcus multilocularis and Taenia taeniformis in Arvicola terrestris. Parasit. Vectors, 4: 6.

12. Panti-May, J.A., Hernandez-Betancourt, S., Ruiz-Pina, H. and Medina-Peralta, S. (2012) Abundance and population parameters of commercial rodents present in rural households in Yucatan, Mexico. Int. Biodeterior. Biodegrad., 66: 77-81.

13. Zeinab, S., Bahador, S., Mohammad, H.M., Qasem, A., Mohammad, J.R. and Samaneh, A.K. (2016) Protozoan parasites of rodents and their zoonotic significance in BoyerAhmad District, Southwestern, Iran. Vet. Med. Int., 2016. Article ID: 32638, 68, 5.

14. Zhao, Z., Wang, R., Zhao, W. and Qi, M. (2015) Genotyping and subtyping of Giardia and Cryptosporidium isolates from commensal rodent in China. Parasitology, 142: 800-806.

15. Marino, M.R., Brown, T.J., Waddington, D.C., Brockie, R.E. and Kelly, P.J. (1992) Giardia intestinalis in North Island possums, house mice and ship rats. N. Zeal. Vet. J., 40: 24-27.

16. Chilvers, B.L., Cowan, P.E., Waddington, D.C., Kelly, P.J. and Brown, T.J. (1998) The prevalence of infection of Giardia spp. and Cryptosporidium spp. in wild animals on farm land, South-Eastern North Island. Int. J. Environ. Health Res., 8: 59-64.

17. Kilonzo, C., Xunde, L., Vivas, E.J., Ray-Russel, M.T., Fernandez, K.L. and Atwill, A.R. (2013) Fecal shedding of zoonotic food-borne pathogens by wild rodents in a major agricultural region of the central California Coast. Appl. Environ. Microbiol., 79: 6337-6344. 